\title{
A new approach for urinary vanillylmandelic acid determination using eVol microextraction by packed sorbent coupled to liquid chromatography-tandem mass spectrometry
}

Xin Xiong ${ }^{1,2^{*}}$ and Yuanyuan Zhang ${ }^{1,2}$

\begin{abstract}
Vanillylmandelic acid (VMA) is one of the most important catecholamine metabolites, and it is usually used to aid in diagnosis of pheochromocytoma and paraganglioma. A new digital control microextraction by packed sorbent (MEPS) procedure coupled to liquid chromatography-mass spectrometry (LC-MS/MS) method has been developed to determine VMA in human urine. We evaluated important parameters influencing MEPS efficiency, including stationary phase, extracting cycles, and sample dilution. In optimized MEPS conditions, Only $10 \mu \mathrm{L}$ of sample volume and 3 min preparation time for one sample were needed. Chromatographic separation was achieved with a hydrophilic interaction liquid chromatography (HILIC) column using gradient elution. VMA was detected using multiple reaction monitoring (MRM) with an electrospray source operating in negative ion mode. The method was validated for linearity, limit of quantification, accuracy, imprecision, matrix effect, and interference. Linearity was 0.5$100 \mathrm{\mu g} / \mathrm{mL}$ for VMA. Intra-assay, inter-assay, and total imprecision were less than 9.6\%. Interferences precluding quantitation of VMA in dilute-and-shoot approach were reduced significantly using a MEPS approach. Method comparison of LC-MS/MS and homogeneous enzyme immunoassay was performed, and the reference interval was established. The developed MEPS-LC-MS/MS method certainly contributes to method robustness and makes it suitable for measurement of urinary VMA in routine clinical biochemistry laboratories.
\end{abstract}

Keywords: Microextraction by packed sorbent, Vanillylmandelic acid, Liquid chromatography-tandem mass spectrometry, Human urine samples, Pheochromocytoma and paraganglioma

\section{Introduction}

Pheochromocytoma and paraganglioma (PPGL) are rare tumors originating from adrenal and extra-adrenal chromaffin cells that are characterized by excessive secretion of large amount of catecholamines (Monteleone et al. 2013). PPGL could lead to various cardiovascular or

\footnotetext{
* Correspondence: xiongxin1029@outlook.com

'Department of Pharmacy, Peking University Third Hospital, Beijing 100191 China

${ }^{2}$ Therapeutic Drug Monitoring and Clinical Toxicology Center of Peking University, Beijing 100191, China
}

\section{Springer Open}

(c) The Author(s). 2020 Open Access This article is licensed under a Creative Commons Attribution 4.0 International License, which permits use, sharing, adaptation, distribution and reproduction in any medium or format, as long as you give appropriate credit to the original author(s) and the source, provide a link to the Creative Commons licence, and indicate if changes were made. The images or other third party material in this article are included in the article's Creative Commons licence, unless indicated otherwise in a credit line to the material. If material is not included in the article's Creative Commons licence and your intended use is not permitted by statutory regulation or exceeds the permitted use, you will need to obtain permission directly from the copyright holder. To view a copy of this licence, visit http://creativecommons.org/licenses/by/4.0/.

cerebrovascular diseases and even death if they are not diagnosed and treated in time. Measurement of urinary vanillylmandelic acid (VMA) is frequently used in both the clinical diagnosis and pathological study of this disease because of non-invasive and easy urine specimen collection (Lionetto et al. 2008).

Biochemical tests for VMA typically are performed using high performance liquid chromatography (HPLC), microcolumn chromatography, gas chromatographymass spectrometry (GC-MS), or immunoassay techniques (Davidson 1989; Tran et al. 2014; Taran et al. 
1997; Tsunoda 2006). Liquid chromatography-tandem mass spectrometry (LC-MS/MS) offers several advantages for polar small molecule metabolites. LC-MS/MS can simplify sample preparation, decrease analysis time, and improve selectivity and sensitivity. In recent years, LC-MS/MS has been developed to determine VMA as a single analyte (Magera et al. 2003; Shen et al. 2015) or in panels with other biomarkers related to neuroendocrine tumors (Lionetto et al. 2008; Clark et al. 2017; Fang et al. 2012; Konieczna et al. 2016; Shen et al. 2019; Grouzmann et al. 2018). Solid phase extraction (SPE) (Magera et al. 2003) and dispersive liquid-liquid microextraction (DLLME) (Konieczna et al. 2016) that were reported for sample cleanup, but dilute-and-shoot method was opted for sample preparation as it was easy and fast (Shen et al. 2015; Clark et al. 2017; Shen et al. 2019; Grouzmann et al. 2018). Although the use of stable isotope-labeled internal standards and designing LC gradients to exclude analytes from suppression zones that can minimize the matrix effects for a quantitative high-throughput clinical assay when using a dilute-andshoot method, these options still provide insufficient robustness. Clark et al. (2017) had observed matrix interferences in $3 \%$ of the specimens, and an alternate LC gradient was designed to resolve the interferences. Recently, microextraction by packed sorbent (MEPS) has evolved a simple, rapid, and environmentally friendly method for extracting a wide range of analytes from different matrices, such as biological fluids (plasma, blood, and urine) (Abdel-Rehim 2011). MEPS is a miniaturized form of SPE technique that approximately $1 \mathrm{mg}$ of the solid phase is built into syringe needle. Several sorbents including silica $(\mathrm{C} 8, \mathrm{C} 18)$, ion exchange material, or molecular imprinted polymers (MIPs) can be employed to extract variety of analytes (Abdel-Rehim 2014; Moein et al. 2014; Chaves et al. 2010; Altun et al. 2004; Saracino et al. 2015). MEPS can be used more than 100 times for plasma or urine samples, but a conventional SPE column is used only once. Furthermore, a digital analytical device named $\mathrm{eVol}^{\circ}$ syringe can couple with MEPS syringe to control the speed and volume of the extraction. The semi-automation of sample processing is compatible with various analytical instruments, including LC-MS equipment. This technique, $\mathrm{eVol}^{\circ}$-MEPS, can meet the requirements of clinical laboratory for the simplicity, rapidity, miniaturization, and small sample volumes of sample preparation and maintain sufficient selectivity, precision, and accuracy.

The aim of the study was to develop and validate a fast, simple, and reliable $\mathrm{eVol}^{\circ}-\mathrm{MEPS}$ procedure combined with the LC-MS/MS method to increase throughput, improve analytical specificity for VMA in urine, and further establish reference interval of VMA to assist in diagnosis of PPGL.

\section{Materials and methods}

Chemicals and materials

VMA and its stable isotopes internal standard, 4hydroxy-3-methoxy-d3-mandelic acid (VMA-d3), were from Sigma-Aldrich (Saint-Louis, Missouri, USA). Lyphocheck ${ }^{\circ}$ Quantitative Controls Levels I and II were purchased from Bio-Rad Clinical Division (Hercules, California, USA). Synthetic urine was prepared by dissolving $0.93 \mathrm{~g}$ of urea, $0.19 \mathrm{~g}$ of $\mathrm{NaCl}$, and $0.07 \mathrm{~g}$ of creatinine in $100 \mathrm{~mL}$ of ultra-pure water; the $\mathrm{pH}$ of the mixture was adjusted to 5.6 (Saracino et al. 2015). All chemicals and reagents were HPLC grade or analytical grade. HPLC-grade acetonitrile and formic acid were from Fisher Scientific (Fair Lawn, New Jersey, USA), and acetic acid, ammonium acetate, and ammonium formate were commercially obtained from Dikma (Lake Forest, USA). Ultra-pure water was obtained using a Milli-Q system (Waters Millipore, Milford, Massachusetts, USA).

\section{Calibration standards and quality controls}

Stock VMA solution was prepared in water at $1000 \mu \mathrm{g} /$ $\mathrm{mL}$. Calibration standards at concentration of $0.5,1,2$, $5,20,50$, and $100 \mu \mathrm{g} / \mathrm{mL}$ were prepared by dilution of the stock solution with synthetic urine. Internal standard (VMA-d3) solution was prepared at a concentration of $20 \mu \mathrm{g} / \mathrm{mL}$ in water.

For the VMA method validation, quality controls (QCs) were prepared at three concentrations: a low QC $(3.50 \mu \mathrm{g} / \mathrm{mL})$, a mid-range QC $(10.0 \mu \mathrm{g} / \mathrm{mL})$, and a high QC $(80.0 \mu \mathrm{g} / \mathrm{mL})$ were made by spiking the stock solutions in healthy specimen pools. Aliquots of stock, calibration, and QCs were stored at $-80^{\circ} \mathrm{C}$.

\section{Sample collection}

Urine samples, collected without preservative over $24 \mathrm{~h}$, were selected from samples submitted for clinical testing. De-identified samples were utilised, and patients were enrolled into the study were approval from the Institutional Review Board of Peking University Third Hospital. The patients kindly consented to do the analysis. Total volumes were measured, and $2 \mathrm{~mL}$ aliquots were stored at $-80{ }^{\circ} \mathrm{C}$ until analysis.

\section{Microextraction by packed sorbent procedure using $\mathrm{eVol}^{\oplus}$ syringe}

Microextraction in packed sorbent was performed using an $\mathrm{eVol}^{\circ}$ semi-automatic syringe from Thermo Fisher Scientific, consisting of $500 \mu \mathrm{L}$ volume syringe coupled with a barrel insert and needle (BIN) assemblies packed with anion exchange (AX) sorbent materials. Before using for the first time, a BIN was conditioned with $3 \times$ $100 \mu \mathrm{L}$ of methanol and $3 \times 100 \mu \mathrm{L}$ of water. Ten microliters of human urine was diluted with $90 \mu \mathrm{L}$ of water. After that, $7 \times 100 \mu \mathrm{L}$ of diluted human urine 
was drawn up and down through the syringe without discarding it. It was important that urine samples were drawn slowly $(20 \mu \mathrm{L} / \mathrm{s})$ to obtain sufficient interaction between the analytes and the sorbent. Then, the sorbent was washed with $100 \mu \mathrm{L}$ of $5 \%$ ammonium hydroxide in water and 5\% ammonium hydroxide in $\mathrm{ACN}$, respectively, to remove biological interferences. The analyte was then eluted by $2 \times 50 \mu \mathrm{L}$ water/ACN 1:1 (v/v) ( $2 \%$ formic acid), and the elution was further diluted with 150 $\mu \mathrm{L}$ water containing $0.7 \%$ ammonium hydroxide. Aliquot of $100 \mu \mathrm{L}$ eluate was transferred into auto-sampler vials for injection. After each extraction, the BIN was rinsed with $4 \times 100 \mu \mathrm{L}$ of water/ACN 1:1 (v/v) ( $2 \%$ formic acid) followed by $100 \mu \mathrm{L}$ of water to prepare it for the following sample. The same AX sorbent could be used for about 150 extractions.

\section{Chromatography and mass spectrometry}

Analysis was performed on a Qtrap 5500 triple quadrupole/linearity ion trap mass spectrometer (Applied Biosystems, Foster City, USA) with an electrospray ionization (ESI) probe in negative mode, which interfaced with a Shimadzu LC-20A HPLC system (Tokyo, Japan) including a degrasser, an autosampler, a binary pump, and a column oven. Data were acquired in multiple reaction monitoring (MRM) mode.

Chromatographic separation was achieved on a ZICHILIC analytical column $(2.1 \times 100 \mathrm{~mm}, 3.5 \mu \mathrm{m}$ particles; Merck, Damstadt, Germany) maintained at $40{ }^{\circ} \mathrm{C}$. The flow rate was $0.3 \mathrm{~mL} / \mathrm{min}$. Mobile phase was composed of acetonitrile (phase A) and $20 \mathrm{mM}$ ammonium formate (phase B) using the following linear gradient program: $0-3.0 \mathrm{~min}$, linear gradient $2-22 \% \mathrm{~B} ; 3.0-4.5$ min, $30 \% \mathrm{~B} ; 4.5-8.0 \mathrm{~min}$, column equilibration. Total run time was $8 \mathrm{~min}$. The injection volume was $1 \mu \mathrm{L}$.

MRM transitions used for quantification and qualification of VMA were m/z $197.0>137.1$ and $197.0>151.1$, respectively. The transitions of VMA-d3 were $\mathrm{m} / \mathrm{z} 200.0$ $>140.1$ (quantifier) and $200.0>154.1$ (qualifier). The optimized MS parameters were as follows: ion source temperature (TEM), $550^{\circ} \mathrm{C}$; curtain gas (CUR), $50 \mathrm{psi}$; collisionally activated dissociation (CAD), media; ion source gas 1, (GS1) 55 psi; ion source gas 2 (GS2), 55 psi; ion-spray voltage (IS), - $3000 \mathrm{~V}$; collision energy (CE), $25 \mathrm{~V}$ for VMA (quantifier), $-15 \mathrm{~V}$ for VMA (qualifier), $-28 \mathrm{~V}$ for VMA-d3 (quantifier), and - 16V for VMAd3 (qualifier); entrance potential (EP), $-12 \mathrm{~V}$ for VMA and $-8 \mathrm{~V}$ for VMA-d3; declustering potential (DP), $37 \mathrm{~V}$ for VMA and - 74 V for VMA-d3; collision cell exit potential (CXP), $-11 \mathrm{~V}$ for VMA and $-18 \mathrm{~V}$ for VMA-d3.

A qualitative ion ratio (QIR) was used to confirm identify of the analytes. The QIRs were calculated as ratios of the peak area for the quantifier transition to the peak area for the qualifier transition for both the analytes and the internal standards. Patient specimen QIR acceptability range was established as $\pm 30 \%$ of the mean value of the QIRs obtained from the calibration standards.

\section{Method validation Linearity and analytical sensitivity}

Linearity was evaluated by analyzing extracted VMA standards spiked in synthetic urine at $0.5,1,2,5,20,50$, and $100 \mu \mathrm{g} / \mathrm{mL}$. Triplicates at each of the seven concentration of VMA were analyzed. Lower limit of quantification (LLOQ) was determined as the lowest measured concentrations with a signal-to-noise $(\mathrm{S} / \mathrm{N})$ ratio greater than 10 with the acceptable criteria of precision of a coefficient variation (CV) below $20 \%$ and accuracy within $80-120 \%$ of expected value.

\section{Imprecision and accuracy}

Three control materials at concentration of 3.5, 10.0, and $80.0 \mu \mathrm{g} / \mathrm{mL}$ were used to estimate imprecision and accuracy on three consecutive days in 5 replicates per run, 1 run per day (total of 15 measurements of each level of control).

\section{Extraction recovery}

To investigate the MEPS recovery of VMA and internal standard in urine samples, two spiked samples using pooled urine were prepared: pre-spiked and post-spiked. The pre-spiked sample was prepared by spiking VMA and internal standard into pooled urine before MEPS, whereas the post-spiked sample was prepared by spiking VMA and internal standard at equivalent concentrations to the extract obtained after MEPS of pooled urine. The percent extraction recovery was calculated as the percent response ratio of VMA and internal standard in the prespiked sample to those in the post-spiked sample.

\section{Carryover}

A set of high $(83.4 \mu \mathrm{g} / \mathrm{mL})$ and low $(1.0 \mu \mathrm{g} / \mathrm{mL})$ concentration samples were injected in a sequence that allows for determination of a mean and standard deviation (SD) for a low concentration sample, and a low concentration sample following a high concentration sample. The injection sequence was low, low, high, and low.

\section{Matrix effect}

Two methods were performed to evaluate the matrix effect (ME). Firstly, the ME was evaluated by the postcolumn infusion study. Urine samples prepared without internal standard were injected into the LC column, and $4 \mu \mathrm{g} / \mathrm{mL}$ internal standard solutions were co-infused at $5 \mu \mathrm{L} / \mathrm{min}$ post-column as described by Annesley (2003). Secondly, the ME was also evaluated by comparing the peak area of VMA-d3 instead of VMA spiked in the 
solution mobile phase with the post-spiked urine samples from six individual sources at the same concentration $(20 \mu \mathrm{g} / \mathrm{mL})$.

\section{Analytical specificity}

Assay interference was tested by analyzing samples spiked with known concentrations of endogenous and exogenous compounds. Recommendations from CLSI EP7-A2, Interference Testing in Clinical Chemistry, were used to guide prepared concentrations of interferences. The potential interferences were spiked into the Lyphocheck $^{\circ}$ Quantitative Controls at two levels (normal and pathological ranges) before extraction.

\section{Stability}

A pool of urine samples spiked with VMA stock solutions was used to assess analyte stability without acid stabilization. The autosampler stability was assessed by keeping the processed QC samples at room temperature for $48 \mathrm{~h}$. The freeze-thaw stability was evaluated by analyzing the QC samples after 3 cycles from $-80{ }^{\circ} \mathrm{C}$ to room temperature. The urine samples were analyzed for bench-top stability after storage at room temperature for $42 \mathrm{~h}$. Aliquots of QC samples were stored at $-80{ }^{\circ} \mathrm{C}$ for 2 months. All the stability studies were conducted at 3 concentration levels with 3 replicates. The stability of the stock solutions was tested and established under refrigeration $\left(\sim 4{ }^{\circ} \mathrm{C}\right)$ for 200 days.

\section{Method comparison and reference interval}

Urine specimens from 39 patients were assayed by the new MEPS-LC-MS/MS method and the previous developed LC-MS/MS using "dilute-and-shoot" sample preparation method in our laboratory which referred to the published method (Clark et al. 2017). Internal standard working solution $(10 \mu \mathrm{L})$ and $0.05 \%(\mathrm{v} / \mathrm{v})$ formic acid in water $(160 \mu \mathrm{L})$ were added to urine samples $(20 \mu \mathrm{L})$ and thoroughly mixed; then, $1 \mu \mathrm{L}$ was injected for determination.

De-identified $24 \mathrm{~h}$ urine specimens submitted for routine testing of VMA by homogeneous enzyme immunoassay (HEI) were also assayed by the new LC-MS/MS method, and the results were compared. Reference interval was evaluated according to the method of Hoffmann (Katayev et al. 2010). Outlier values exceeding the third quartile plus three times the interquartile range were removed. Reference limits were calculated as the central $95 \%$ based on extrapolation of the linear portion of the data.

\section{Data analysis}

The analyst 1.5.2 software (Applied Biosystems, Forster City, USA) and GraphPad Prism 5.0 (GraphPad
Software, San Diego California, USA) were applied to statistical evaluation of the data.

\section{Results and discussions Optimization of chromatographic conditions}

VMA is a low molecular weight and polar compound with poor retention time in regular reversed-phase liquid chromatography (RP-LC). In order to achieve satisfactory retention and to avoid interference from the background, the alternative LC-MS method based on hydrophilic interaction liquid chromatography (HILIC) was developed for successful determination of polar compounds (Kumar et al. 2011). ZIC-HILIC column with packing zwitterionic stationary phase was selected to retain VMA. The composition of mobile phase, buffer type, and $\mathrm{pH}$ value was investigated for appropriate resolution, good peak shape, and response of VMA. As the percentage of the organic solvent in the mobile phase increases, the retention factor increases in HILIC mode, and high ratio of $\mathrm{ACN}$ was used. The effect of buffer concentration in the mobile phase was investigated. Thus, ammonium acetate and ammonium formate were tested due to their solubility in high amount of organic modifier. The buffer concentration varied from 1 to 40 $\mathrm{mM}$. Although the retention of VMA increased with buffer concentration increased, higher concentrations of salt additives can result in signal suppression for mass spectrometric detection as we all know. Therefore, the best retention and significantly better ionization was obtained when $20 \mathrm{mM}$ ammonium formate buffer was used. To evaluate $\mathrm{pH}$ influence on retention time of VMA, ammonium formate buffers containing different amount of formic acid (0.0-0.5\%) were tested. Higher acidic concentration resulted in decreased retention time, so optimal retention time for VMA, was noticed under without formic acid additive. Example chromatograms of VMA calibration standard and of healthy and abnormal patient specimens are shown in Fig. 1.

\section{Optimization of $\mathrm{eVol}^{\oplus}$ MEPS procedure}

In this study, several parameters related to MEPS were optimized using $1 \mu \mathrm{g} / \mathrm{mL}$ of VMA of standard solutions. Optimized parameters included sorbent type, sample volume, and elution conditions which strongly affect the extraction efficiency of MEPS. Firstly, four commercially available MEPS sorbents (C8, C18, SIL, and R-AX) were investigated. Sufficient retention of VMA on the R-AX sorbent was obtained due to anionic exchange interaction.

Retention of VMA on R-AX sorbent was affected by the number of extraction cycles. The different number of cycles increases the extraction efficiency (Fig. 2a). The results obtained indicated that the response was the strongest for the load 7 times. Higher number of 


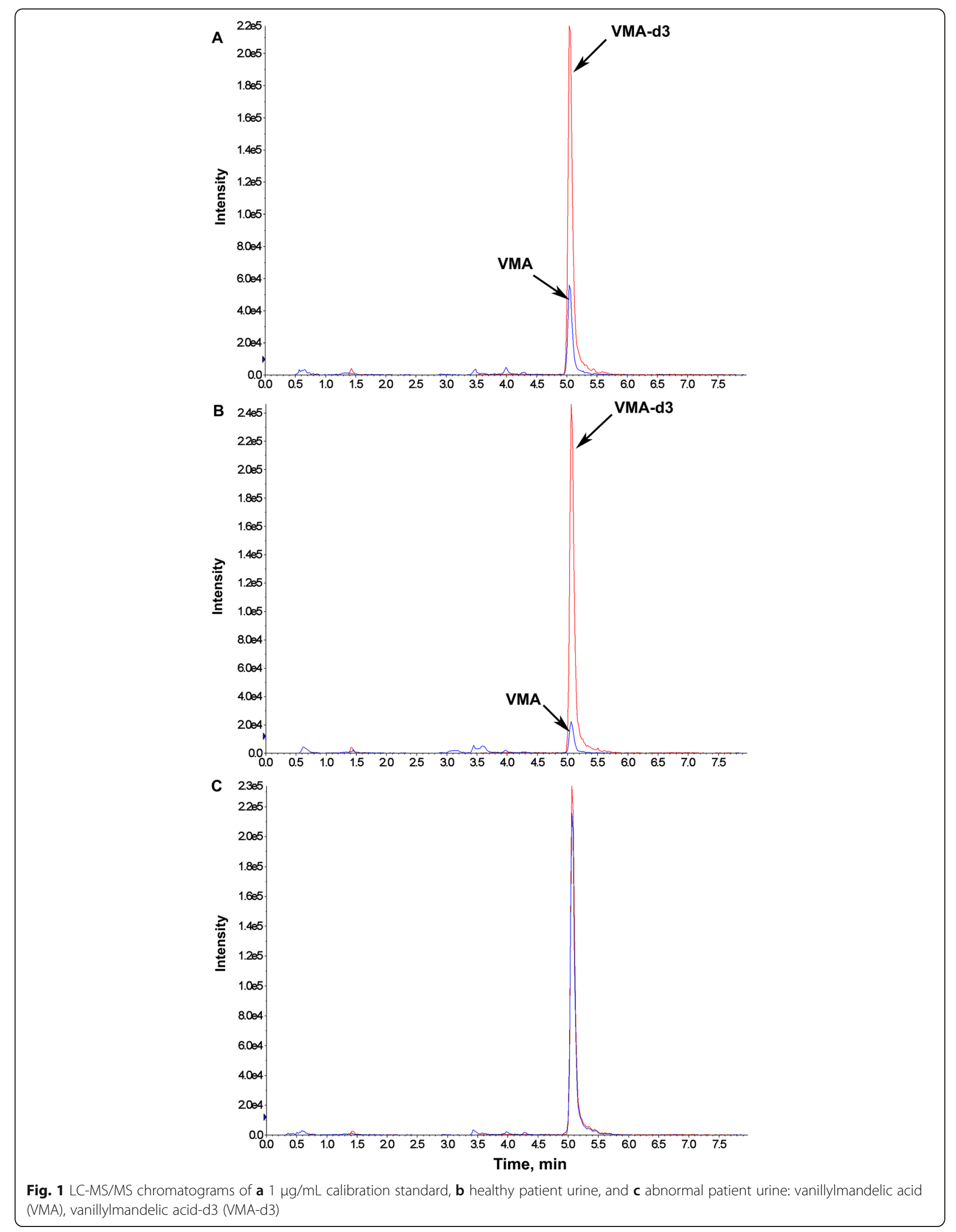



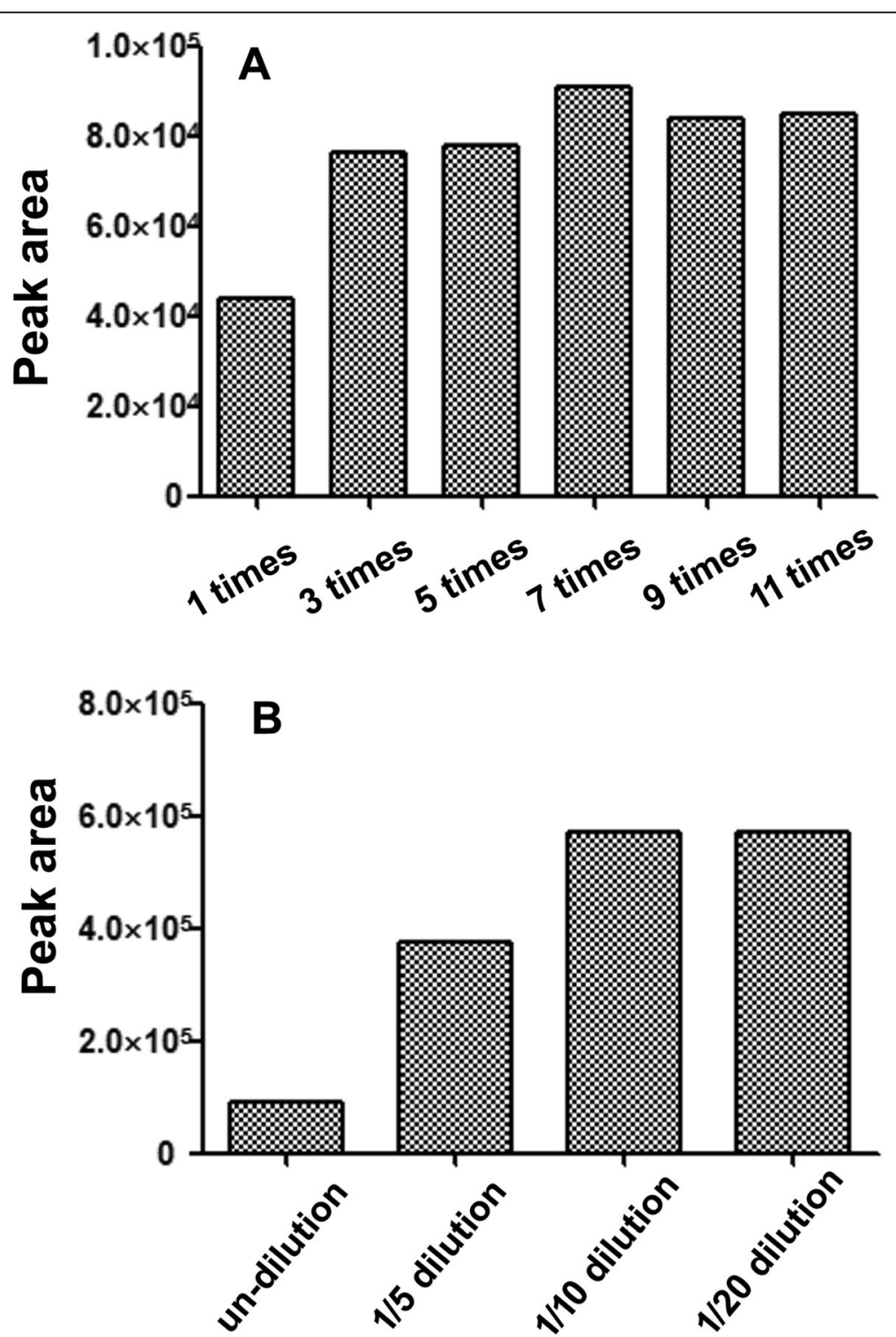

Fig. 2 Influence of different parameters on MEPS efficiency. a Effect of the number of extraction cycles on the VMA response. $\mathbf{b}$ Effect of the urine dilution folds on the VMA response

Table 1 Intra-assay, inter-assay accuracy, and imprecision for VMA in human urine

\begin{tabular}{|c|c|c|c|c|c|c|c|c|}
\hline \multirow[t]{2}{*}{ Analytes } & \multirow{2}{*}{$\begin{array}{l}\text { Concentration } \\
(\mu \mathrm{g} / \mathrm{mL})\end{array}$} & \multicolumn{3}{|l|}{ Intra-assay } & \multicolumn{3}{|l|}{ Inter-assay } & \multirow{2}{*}{$\begin{array}{l}\text { Total } \\
(\% \mathrm{CV}\end{array}$} \\
\hline & & Mean \pm SD $(\mu \mathrm{g} / \mathrm{mL})$ & Accuracy (\%) & CV (\%) & Mean \pm SD $(\mu \mathrm{g} / \mathrm{mL})$ & Accuracy (\%) & CV (\%) & \\
\hline \multirow[t]{4}{*}{$\overline{V M A}$} & 0.500 & $0.550 \pm 0.040$ & 110.0 & 7.3 & $0.532 \pm 0.033$ & 106.4 & 6.3 & 9.6 \\
\hline & 3.50 & $3.60 \pm 0.18$ & 102.9 & 4.9 & $3.40 \pm 0.22$ & 97.1 & 6.4 & 8.1 \\
\hline & 10.0 & $11.1 \pm 0.5$ & 111.0 & 3.3 & $10.7 \pm 0.6$ & 107.0 & 3.9 & 5.1 \\
\hline & 80.0 & $83.6 \pm 4.0$ & 104.5 & 4.6 & $80.6 \pm 4.8$ & 100.8 & 5.7 & 7.3 \\
\hline
\end{tabular}


extraction cycles did not significantly improve the extraction efficiency and might shorten the lifetime of the MEPS sorbent as complex matrix could saturate the stationary phase with interferences.

The key steps for optimal extraction were using basic washing solvent to convert the VMA into ionized molecule in order to make it retained on R-AX sorbent and secondly, acidic elution solvent to convert it into neutral molecule and to elute it from the sorbent. Therefore, $5 \%$ ammonium hydroxide in water followed by $5 \%$ ammonium hydroxide in ACN was employed as the most appropriate washing solvents. For the elution step, $2 \times 50$ $\mu \mathrm{L}$ of $2 \%$ formic acid in $\mathrm{ACN}$ :water $(1: 1, \mathrm{v} / \mathrm{v})$ was chosen.

Then, the developed procedure was applied on urine specimens spiked with VMA. A significant leak of the analytes from the MEPS sorbent was observed after the sample loaded. It was probably caused by a strong competition for the sorbent active sites between the analytes and other ions presented in urine. The use of buffer with different $\mathrm{pH}$ did not prevent the leakage of analytes. Therefore, dilution of urine was subsequently tested in order to eliminate the competition. From Fig. 2b, we could see that the leakage did not occur when the urine was diluted 10 times with water.

\section{Method validation results}

\section{Linearity and analytical sensitivity}

Linearity of the developed method was established with the use of seven calibration curves analyzed in triplicate in the nominal concentration range from $0.5-100 \mu \mathrm{g} /$ $\mathrm{mL}$ in synthetic urine samples. From the calibration curve, the linear equation was $y=0.066 x+0.000754\left(r^{2}\right.$
$=0.9984$ ), which demonstrated good linearity for quantification. The LLOQ for VMA was $0.5 \mu \mathrm{g} / \mathrm{mL}$ with interassay CV of $6.3 \%$, which was sufficient for accurate measurement of samples.

\section{Imprecision and accuracy}

Imprecision calculated as the $\mathrm{CV}$ for three control materials at low, medium, and high concentration levels was assayed by analyzing five replicates for each day over 3 days. The intra-assay, inter-assay, and total imprecision for VMA were ranged from 1.9 to $9.6 \%$, which demonstrated excellent precision of the method for quantification. Specific data are listed in Table 1.

Accuracy was assessed five replicates at three concentration levels over 3 days by spiking known amounts of VMA into urine samples. The intra-assay, inter-assay, and total accuracy for $3 \mathrm{QC}$ concentrations were in the range of 98.8 to $110.0 \%$ (shown in Table 1), which indicated excellent accuracy of this method for clinical application.

\section{Extraction recovery}

The extraction recovery of the MEPS method was evaluated by spiking a pool urine with known amounts of VMA at three concentration levels $(1,10$, and $80 \mu \mathrm{g} / \mathrm{mL})$. The absolute recoveries determined for three different concentrations of VMA were ranged from $57.5-70.5 \%$.

\section{Carryover}

The carryover was investigated by injecting low, low, high, and low concentration samples in sequence. The calculated carryover values for VMA were $0.007 \mu \mathrm{g} / \mathrm{mL}$ which was less than the error limits $(0.027 \mu \mathrm{g} / \mathrm{mL})$, defined as three

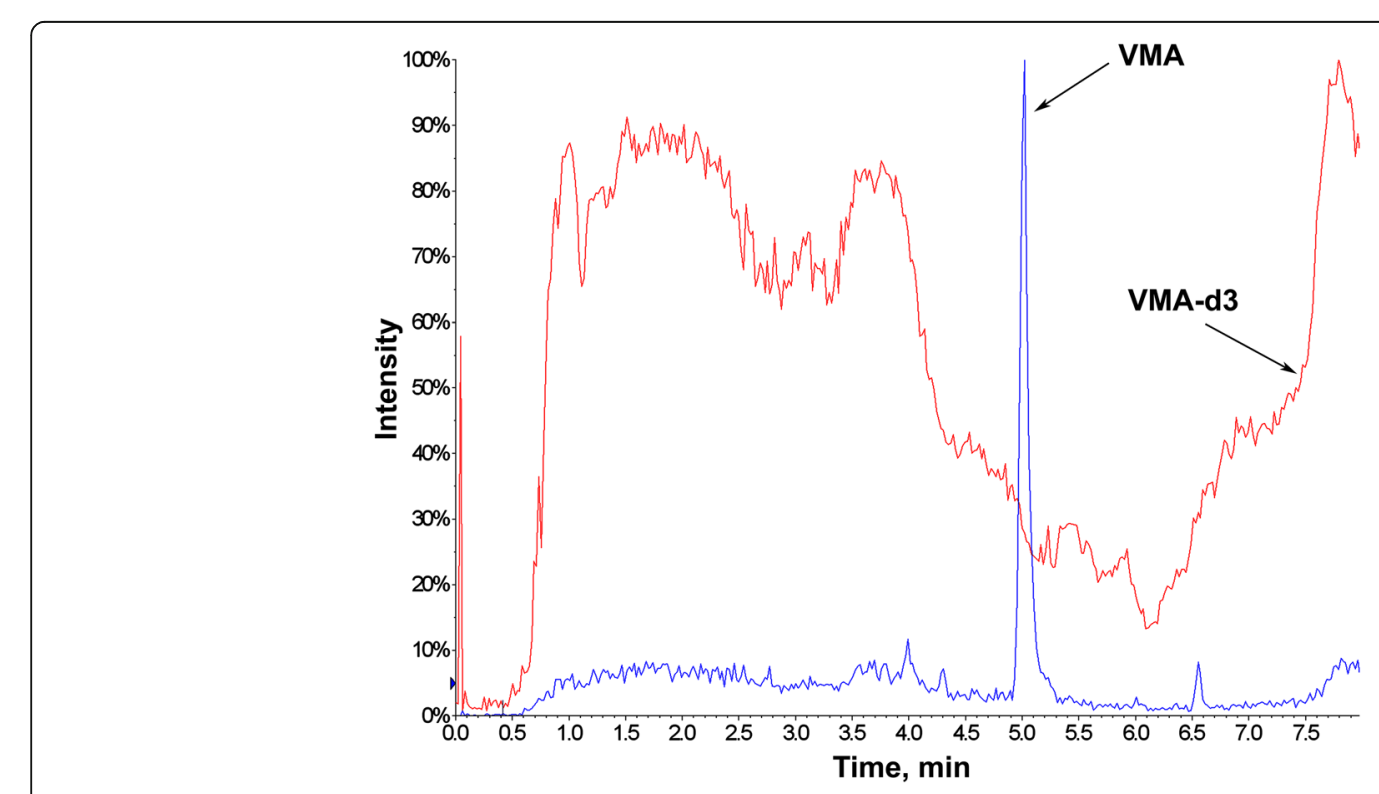

Fig. 3 Post-column infusion experiment 
Table 2 Deviations from baseline concentrations of VMA for exogenous potential interferences

\begin{tabular}{|c|c|c|c|c|}
\hline Substances & Test concentration $(\mu \mathrm{g} / \mathrm{mL})$ & VMA mean $(\mu \mathrm{g} / \mathrm{mL})$ & VMA determined $(\mu \mathrm{g} / \mathrm{mL})$ & VMA deviation (\%) \\
\hline \multirow[t]{2}{*}{ Theobromine } & \multirow[t]{2}{*}{100} & 2.93 & 2.87 & -2.0 \\
\hline & & 15.8 & 15.1 & -4.4 \\
\hline \multirow[t]{2}{*}{ Acetaminophen } & \multirow[t]{2}{*}{200} & 2.93 & 3.05 & 4.1 \\
\hline & & 15.8 & 16.2 & 2.5 \\
\hline \multirow[t]{2}{*}{ Labetalol } & \multirow[t]{2}{*}{100} & 2.93 & 2.76 & -5.8 \\
\hline & & 15.8 & 16 & 1.3 \\
\hline \multirow[t]{2}{*}{ Amitriptyline } & \multirow[t]{2}{*}{10} & 2.93 & 2.7 & -7.9 \\
\hline & & 15.8 & 14.9 & -5.7 \\
\hline \multirow[t]{2}{*}{ Pseudoephedrine } & \multirow[t]{2}{*}{10} & 2.93 & 2.79 & -4.8 \\
\hline & & 15.8 & 15.6 & -1.3 \\
\hline \multirow[t]{2}{*}{ Diphenhydramine } & \multirow[t]{2}{*}{10} & 2.93 & 2.96 & 1.0 \\
\hline & & 15.8 & 15.4 & -2.5 \\
\hline \multirow[t]{2}{*}{ Theophylline } & \multirow[t]{2}{*}{100} & 2.93 & 2.9 & -1.0 \\
\hline & & 15.8 & 17 & 7.6 \\
\hline \multirow[t]{2}{*}{ Carbidopa } & \multirow[t]{2}{*}{100} & 2.93 & 2.84 & -3.1 \\
\hline & & 15.8 & 17.4 & 10.1 \\
\hline \multirow[t]{2}{*}{ Levodopa } & \multirow[t]{2}{*}{100} & 2.93 & 2.89 & -1.4 \\
\hline & & 15.8 & 16 & 1.3 \\
\hline \multirow[t]{2}{*}{ Salicylic acid } & \multirow[t]{2}{*}{1000} & 2.93 & 3.18 & 8.5 \\
\hline & & 15.8 & 16 & 1.3 \\
\hline \multirow[t]{2}{*}{ Clonidine } & \multirow[t]{2}{*}{10} & 2.93 & 3.13 & 6.8 \\
\hline & & 15.8 & 17.3 & 9.5 \\
\hline \multirow[t]{2}{*}{ Isoetharine } & \multirow[t]{2}{*}{100} & 2.93 & 2.85 & -2.7 \\
\hline & & 15.8 & 17.8 & 12.7 \\
\hline \multirow[t]{2}{*}{ Isoproterenol } & 100 & 2.93 & 2.92 & -0.3 \\
\hline & & 15.8 & 15.3 & -3.2 \\
\hline 3-O-methyl-dopa & 10 & 2.93 & 3.11 & 6.1 \\
\hline & & 15.8 & 16.7 & 5.7 \\
\hline Methyldopa & 100 & 2.93 & 2.89 & -1.4 \\
\hline & & 15.8 & 16.1 & 1.9 \\
\hline $\mathrm{MDA}^{1}$ & 100 & 2.93 & 3.37 & 15.0 \\
\hline & & 15.8 & 17.1 & 8.2 \\
\hline $\mathrm{HMMA}^{2}$ & 100 & 2.93 & 3.13 & 6.8 \\
\hline & & 15.8 & 16.5 & 4.4 \\
\hline PMMA $^{3}$ & 100 & 2.93 & 2.73 & -6.8 \\
\hline & & 15.8 & 15 & -5.1 \\
\hline (phentermine, $\mathrm{MDEA}^{5}$, amphetamine, $\mathrm{MDMA}^{6}, \mathrm{MA}^{7}$ ) mixture & 100 & 2.93 & 2.85 & -2.7 \\
\hline & & 15.8 & 16.2 & 2.5 \\
\hline (ibuprofen, naproxen, cotinine, nicotine, caffeine) mixture & 1000 & 2.93 & 2.86 & -2.4 \\
\hline & & 15.8 & 16.1 & 1.9 \\
\hline Carbamazepine & 1000 & 2.93 & 2.76 & -5.8 \\
\hline & & 15.8 & 16.1 & 1.9 \\
\hline
\end{tabular}

13,4-Methylenedioxyamphetamine

24-Hydroxy-3-methoxymethamphetamine

${ }^{3} 4$-Methoxymethamphetamine

53,4-Methylenedioxyethylamphetamine

${ }^{6}$ 3,4-Methylenedioxymethpheamphetamine

${ }^{7}$ Methamphetamine 
Table 3 Deviations from baseline concentrations of VMA for endogenous potential interferences

\begin{tabular}{|c|c|c|c|c|}
\hline Substances & Test concentration $(\mu \mathrm{g} / \mathrm{mL})$ & VMA mean $(\mu \mathrm{g} / \mathrm{mL})$ & VMA determined $(\mu \mathrm{g} / \mathrm{mL})$ & VMA deviation (\%) \\
\hline \multirow[t]{2}{*}{ Tryptophan } & 200 & 2.93 & 2.8 & -4.4 \\
\hline & & 15.8 & 16.1 & 1.9 \\
\hline \multirow[t]{2}{*}{ Phenylalanine } & 200 & 15.8 & 17 & 7.6 \\
\hline & & 15.8 & 17.2 & 8.9 \\
\hline \multirow[t]{2}{*}{ Tyrosine } & 1000 & 2.93 & 2.81 & -4.1 \\
\hline & & 15.8 & 16.8 & 6.3 \\
\hline \multirow[t]{2}{*}{ Melatonin } & 165 & 2.93 & 2.8 & -4.4 \\
\hline & & 15.8 & 14.6 & -7.6 \\
\hline \multirow[t]{2}{*}{ Uric acid } & 500 & 2.93 & 2.7 & -7.9 \\
\hline & & 15.8 & 15.8 & 0.0 \\
\hline \multirow[t]{2}{*}{ Ascorbic acid } & 200 & 2.93 & 2.98 & 1.7 \\
\hline & & 15.8 & 16.5 & 4.4 \\
\hline \multirow[t]{2}{*}{ Urea } & 2000 & 2.93 & 2.82 & -3.8 \\
\hline & & 15.8 & 15.5 & -1.9 \\
\hline \multirow[t]{2}{*}{ Glucose } & 2000 & 2.93 & 3.06 & 4.4 \\
\hline & & 15.8 & 16.3 & 3.2 \\
\hline \multirow[t]{2}{*}{ Riboflavin } & 108 & 2.93 & 3.21 & 9.6 \\
\hline & & 15.8 & 15.5 & -1.9 \\
\hline \multirow[t]{2}{*}{ 4-OH-3-methoxyphenyl glycol } & 1000 & 2.93 & 3.02 & 3.1 \\
\hline & & 15.8 & 15 & -5.1 \\
\hline \multirow[t]{2}{*}{ 5-Hydroxytryptophol } & 100 & 2.93 & 3.27 & 11.6 \\
\hline & & 15.8 & 16.5 & 4.4 \\
\hline \multirow[t]{2}{*}{ Nicotinamide } & 500 & 2.93 & 2.7 & -7.9 \\
\hline & & 15.8 & 15.5 & -1.9 \\
\hline \multirow[t]{2}{*}{ Pyridoxal 5-phosphate } & 500 & 2.93 & 3.04 & 3.8 \\
\hline & & 15.8 & 15.4 & -2.5 \\
\hline \multirow[t]{2}{*}{ Thiamine } & 200 & 2.93 & 2.87 & -2.1 \\
\hline & & 15.8 & 16.2 & 2.5 \\
\hline \multirow[t]{2}{*}{ Nicotinurirc acid } & 200 & 2.93 & 2.85 & -2.7 \\
\hline & & 15.8 & 14.6 & -7.6 \\
\hline \multirow[t]{2}{*}{ Nicotinic acid } & 200 & 2.93 & 2.82 & -3.8 \\
\hline & & 15.8 & 15.7 & -0.6 \\
\hline \multirow[t]{2}{*}{ Pyridoxal } & 200 & 2.93 & 2.84 & -3.1 \\
\hline & & 15.8 & 15.3 & -3.2 \\
\hline \multirow[t]{2}{*}{ 5-Hydroxyindoleacetic acid } & 100 & 2.93 & 2.87 & -2.1 \\
\hline & & 15.8 & 15 & -5.1 \\
\hline \multirow[t]{2}{*}{ Metanephrine } & 100 & 2.93 & 3 & 2.4 \\
\hline & & 15.8 & 15.9 & 0.6 \\
\hline \multirow[t]{2}{*}{ 3-Methoxytyramine } & 200 & 2.93 & 2.92 & -0.3 \\
\hline & & 15.8 & 14.8 & -6.3 \\
\hline \multirow[t]{2}{*}{ Norepinephrine } & 100 & 2.93 & 2.86 & -2.4 \\
\hline & & 15.8 & 15.2 & -3.8 \\
\hline \multirow[t]{2}{*}{ Normetanephrine } & 100 & 2.93 & 2.9 & -1.0 \\
\hline & & 15.8 & 15.4 & -2.5 \\
\hline 3,4-Dihydroxymandelic acid & 1000 & 2.93 & 3.25 & 10.9 \\
\hline & & 15.8 & 14.8 & -6.3 \\
\hline 3,4-Dihydroxyphenylacetic acid & 1300 & 2.93 & 3.12 & 6.5 \\
\hline & & 15.8 & 16.2 & 2.5 \\
\hline
\end{tabular}


Table 4 Urine stability experiment $(n=3)$

\begin{tabular}{|c|c|c|c|c|c|c|}
\hline \multirow{2}{*}{$\begin{array}{l}\text { Concentration } \\
(\mu \mathrm{g} / \mathrm{mL})\end{array}$} & \multicolumn{2}{|c|}{ Room temperature (42 h) } & \multicolumn{2}{|c|}{3 freeze-thaw cycle $\left(-80^{\circ} \mathrm{C}\right)$} & \multicolumn{2}{|c|}{ Long-term storage $\left(-80^{\circ} \mathrm{C}, 56\right.$ days) } \\
\hline & Deviation (\%) & CV (\%) & Deviation (\%) & CV (\%) & Deviation (\%) & CV (\%) \\
\hline 3.50 & -6.6 & 3.2 & -2.3 & 5.0 & 2.3 & 3.0 \\
\hline 10.0 & 2.3 & 2.9 & 13.3 & 2.4 & 0.3 & 2.8 \\
\hline 80.0 & 1.1 & 2.2 & 10.0 & 2.8 & -4.3 & 4.5 \\
\hline
\end{tabular}

times the SD of 2 consecutive low results. In consideration of the upper limits of reference interval, the carryover did not influence the diagnosis of PPGL. Therefore, the carryover was not observed in this LC-MS/MS method.

\section{Matrix effect}

Complex biological samples are exposed to potential ion suppression, especially with electrospray ionization mass spectrometry. The ME was assessed by a post-column infusion using a large number of specimens $(n=105)$.
All of the co-infusion tests showed similar slightly suppression zones at the retention times of the analytes (Fig. 3). Furthermore, the deuterated internal standards elute very closely with their non-labeled analogs that could compensate well for the signal suppression unless it was severe. Moreover, the absolute ME of VMA-d3 is calculated as $\mathrm{Ai} / \mathrm{Ai}^{\prime} \times 100 \%\left(\mathrm{Ai}\right.$ and $\mathrm{Ai}^{\prime}$ represent the peak areas of VMA-d3 within and without matrix). The results showed that the mean absolute ME was $73.0 \%$ with CV of $11.0 \%$.
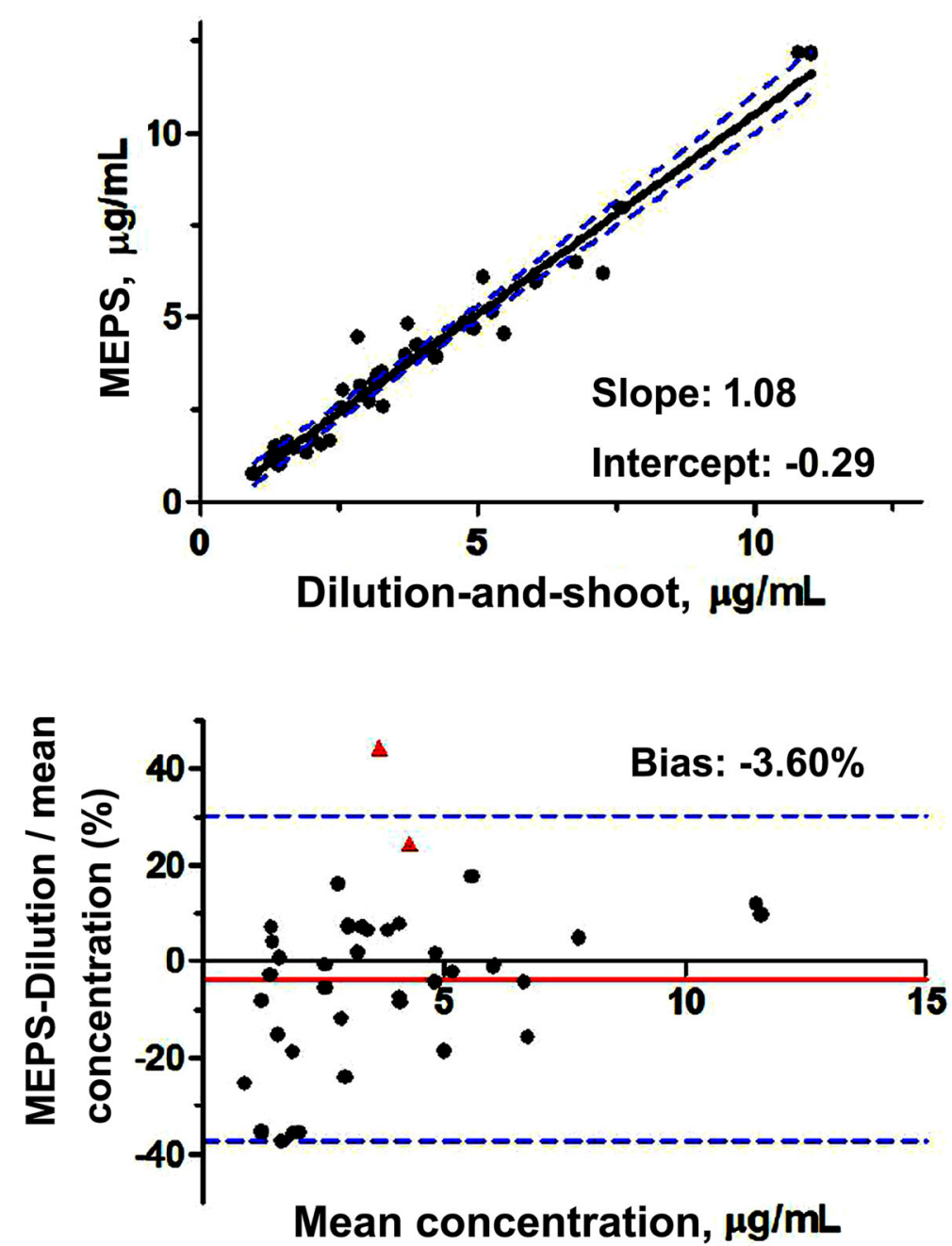

Fig. 4 Comparison between the MEPS-LC-MS/MS and dilute-and-shoot LC-MS/MS assays. Upper plots: weighed Deming fits (solid black lines); lower plots: Bland-Altman analyses (solid black lines). The dotted red lines represent the $95 \%$ limit of agreement 

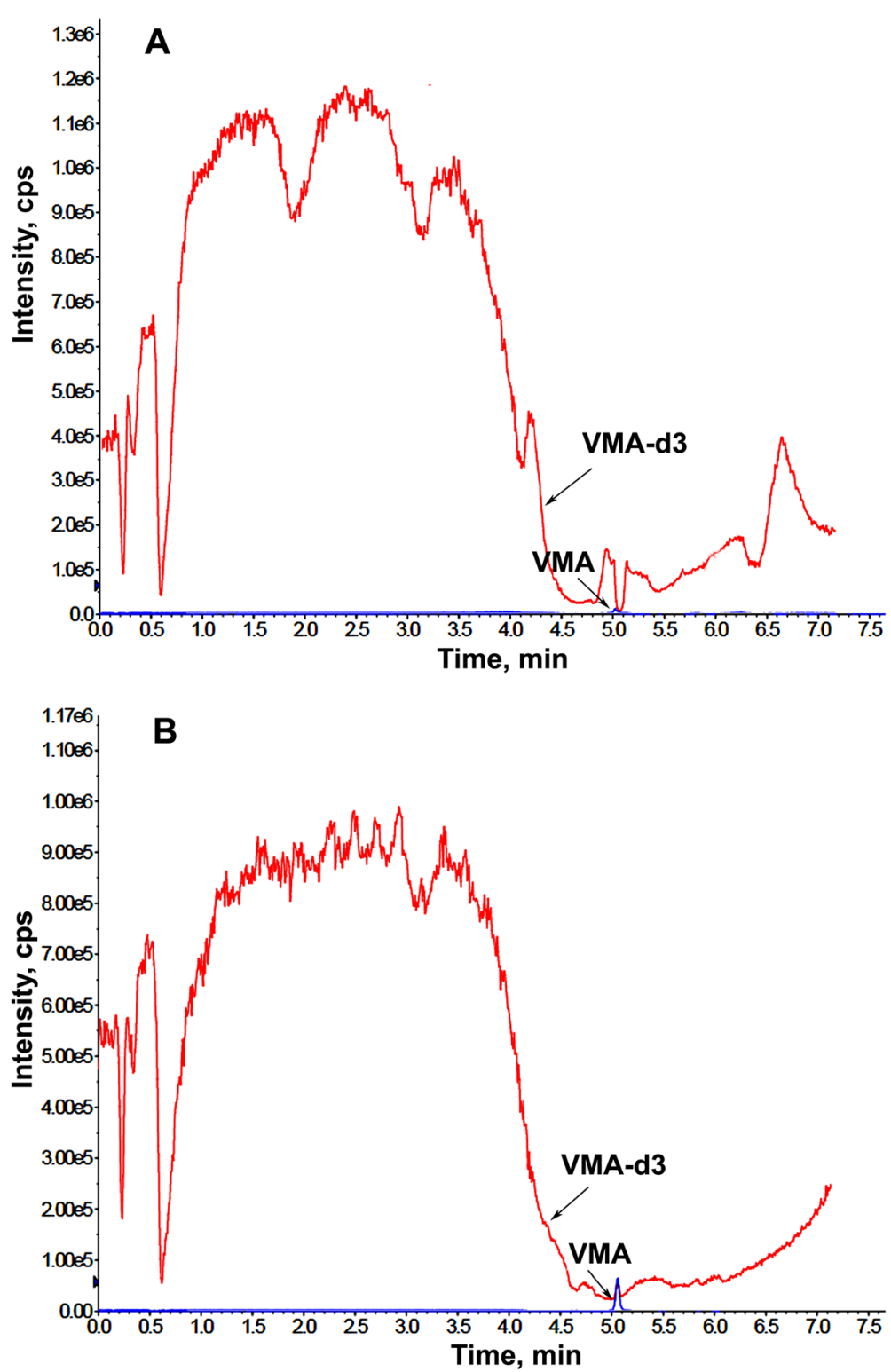

Fig. 5 Mitigation of VMA signal suppression by the MEPS approach. a Dilute-and-shoot approach. b MEPS approach. VMA-d3 was infusion post-column

Therefore, it demonstrated that the determination of VMA was not significantly influenced by the matrix effect. In comparison to dilute-and-shoot sample preparation, the developed MEPS technique can considerably reduce biological matrix influence as clean as SPE procedure. Furthermore, MEPS procedure is highly selective, reproducible, and involves a shorter sample preparation time: a reduced number of reagents and sample volume to comparison to SPE.

\section{Analytical specificity}

Exogenous and endogenous compounds evaluated as potential interferences are listed in Tables 2 and 3, respectively. Percent bias, calculated as a ratio of analyte concentrations in the spiked vs. baseline sample, was used as a measure of interference. The bias for all tested compounds was between $-7.9 \%$ and $15.0 \%$ for VMA, indicating no interference from any of the compounds tested.

\section{Stability}

To evaluate the stability of non-acidified urine samples, urine QC samples spiked with VMA stock solutions were analyzed at different conditions. The stability of urinary VMA was evaluated at room temperature for $42 \mathrm{~h}$, after three freeze-thaw cycles 

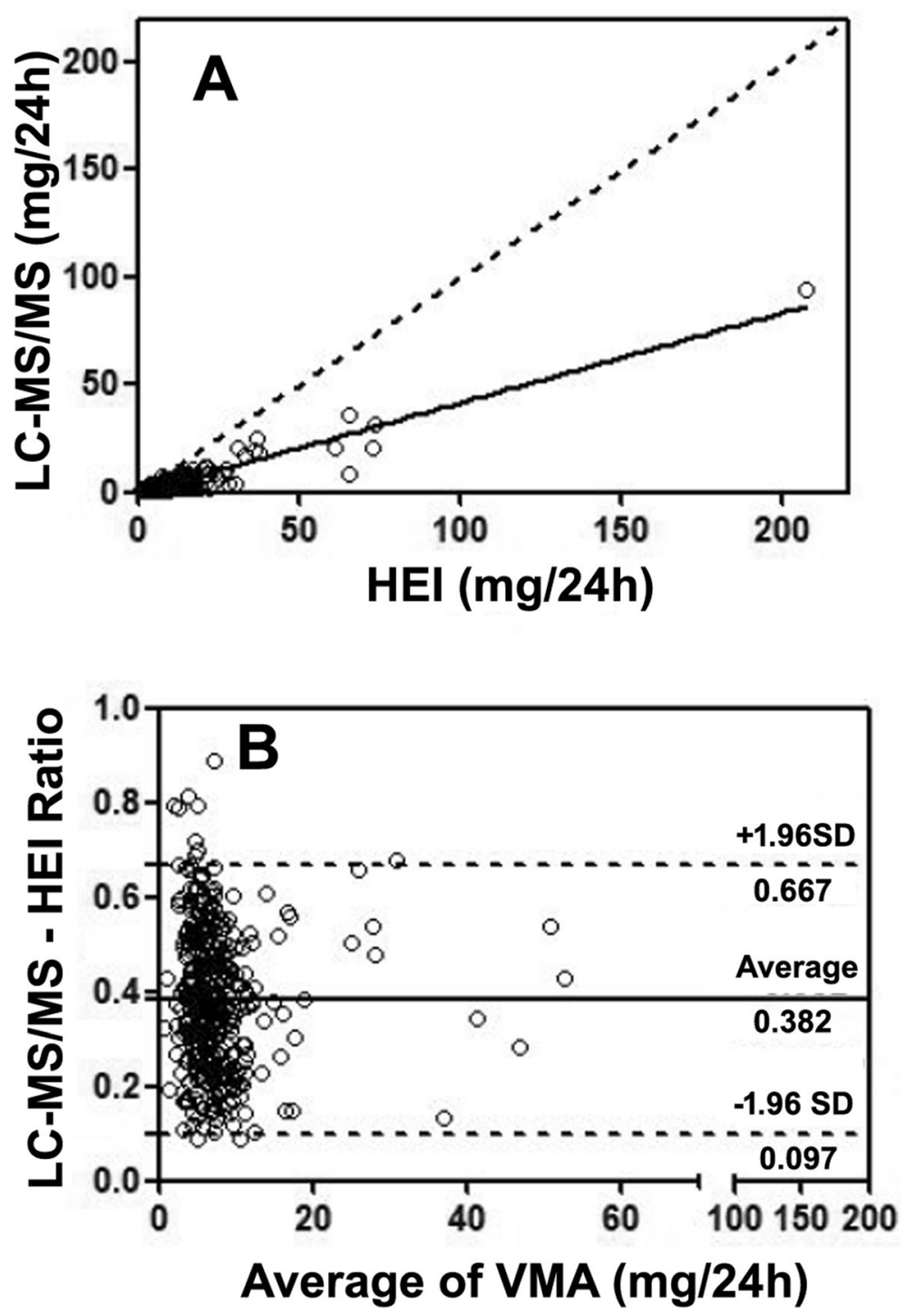

Fig. 6 Method comparison of LC-MS/MS and HEl method for the analysis of VMA. a Scatter plots of VMA results by LC-MS/MS ( $y$ axes) vs by the HEl method ( $x$ axes). b Bland-Altman plots of ratio $(y$ axes) vs average values ( $x$ axes) for VMA results by the LC-MS/MS and HEI method

and long-term storage for 56 days at $-80^{\circ} \mathrm{C}$. The results are listed in Table 4 , indicating that the analytes remained considerably stable under the above conditions. The good stability of VMA simplified the precautions needed for laboratory manipulations during the assay procedures. In addition, stock solution of VMA was shown to be stable at $4{ }^{\circ} \mathrm{C}$ for 200 days.

\section{Method comparison and reference interval}

The concentrations of VMA in urine samples from patients $(n=39)$ were measured by the new MEPSLC-MS/MS method and the previous developed LCMS/MS using "dilute-and-shoot" sample preparation method (Clark et al. 2017) and evaluated with a
Bland-Altman analysis and a Deming fit (Fig. 4). The Bland-Altman analysis highlighted no significant systematic bias between the two methods with a mean difference of $-3.60 \%$ for the determined concentrations of VMA. The corresponding Deming fit revealed good agreement between both assays with a regression slope of 1.08 for VMA.

However, 2 specimens of VMA results in the tested samples could not be reported due to interference when using "dilute-and-shoot" sample preparation (the red triangles in Fig. 4). The majority of the VMA interferences produced internal standard peak areas below the lower acceptance limit $(50 \%$ of the batch internal standard peak area median) due to signal suppression by matrix components at the retention 
time of VMA. In order to compare the 2 specimens with interference using MEPS and dilute-and-shoot approaches, post-column infusion of a VMA-d3 solution was used as a tool to observe the position of suppression zones in the 2 specimens (see Fig. 5). Reanalysis of 2 specimens showed that interference produced VMA peak areas approximately 10-fold higher when using the MEPS approach instead of dilute-andshoot approach, indicating that the MEPS approach could significantly mitigate signal suppression experience by VMA and reduced the incidence of nonreportable results.

Reference interval for VMA by the LC-MS/MS method was verified using statistical analysis (the central $95 \%$ of the rank-ordered data) and was based on the analysis of urine samples, collected from the control group of 215 patients (F, 104, M, 111) in whom the diagnosis of PPGL had been excluded. The established reference interval for VMA was 0$6.21 \mathrm{mg} / 24 \mathrm{~h}(0-31.36 \mu \mathrm{mol} / 24 \mathrm{~h})$ which are within the parameters of Mayo Clinic reference interval (Magera et al. 2003) $(\mathrm{VMA}=0.0-43.37 \mu \mathrm{mol} / 24 \mathrm{~h})$. These results showed the excellent application of this method in clinical laboratories.

In addition, 420 urine specimens successfully analyzed by the HEI method were retested using this new method. The Deming regression shown in Fig. 6a, for these two methods, yielded slopes of 0.421 (95\% CI, 0.404 to 0.437$)$ and $y$-intercepts of $-0.606(95 \% \mathrm{CI}$, 0.886 to -0.326 ), indicating a significantly difference between LC-MS/MS and HEI methods. Using BlandAltman plots (Fig. 6b), the mean difference for LC-MS/ MS results was approximately $62 \%$ lower compared to the HEI results. More than $97 \%$ of compared values differed by less than $2 \mathrm{SD}$. On the basis of these correlation parameters, the LC-MS/MS method will improve specificity, sensitivity, and repeatability.

\section{Conclusions}

A novel MEPS technique with semi-automated $\mathrm{eVol}^{\circ}$ syringe followed by the LC-MS/MS method was developed for the analysis of urinary VMA. This method utilizes $\mathrm{eVol}^{\circ}$ MEPS sample preparation which is efficient decoupling of analytes from the matrix, reduced matrix interference, solvent consumption, and sample volume. R-AX sorbent was used as the stationary phase for sample preparation without loss of selectivity with the re-use of MEPS packing material for about 150 extractions. The developed method is simple, rapid, specify, and robust which has a significant potential as a clinical tool and is suitable for routine clinical laboratory.

\section{Abbreviations}

PPGL: Pheochromocytoma and paragangliomas; CAs: Catecholamines; VMA: Vanillylmandelic acid; DLLME: Dispersive liquid-liquid microextraction;
SPE: Solid phase extraction; MEPS: Microextraction by packed sorbent; MIPS: Molecular imprinted polymers; LLOQ: Lower limit of quantification; ESI: Electrospray ionization; MRM: Multiple reaction monitoring; HILIC: Hydrophilic interaction liquid chromatography; QIR: Qualitative ion ratio; ME: Matrix effect; SD: Standard deviation

\section{Acknowledgements}

Not applicable in this section.

\section{Authors' contributions}

$X X$ designed the study. Clinical specimens were collected by $X X$ and $Z Y Y$. The LC-MS/MS analysis work was executed by ZYY and $X X$, and $X X$ finished the draft of the manuscript. All authors read and approved the final manuscript.

\section{Funding}

This work was supported by the National Natural Science Foundation of China under Grant number 81672107 and the National Natural Science Foundation of China under Grant number 21405007.

\section{Availability of data and materials}

The datasets used and/or analyzed during the current study are available from the corresponding author on reasonable request.

\section{Competing interests}

The authors declare that they have no conflict of interest.

Received: 27 April 2020 Accepted: 25 June 2020

Published online: 08 July 2020

\section{References}

Abdel-Rehim M. Microextraction by packed sorbent (MEPS): a tutorial. Anal Chim Acta. 2011;701:119-28.

Abdel-Rehim M. New trend in sample preparation: on-line microextraction in packed syringe for liquid and gas chromatography applications I. Determination of local anaesthetics in human plasma samples using gas chromatography-mass spectrometry. J Chromatogr B. 2014;801:317-21.

Altun Z, Abdel-Rehim M, Blomberg LG. New trends in sample preparation: online microextraction in packed syringe (MEPS) for LC and GC applications: part III: determination and validation of local anaesthetics in human plasma samples using a cation-exchange sorbent, and MEPS-LC-MS-MS. J Chromatogr B. 2004;813:129-35.

Annesley TM. Ion suppression in mass spectrometry. Clin Chem. 2003:49:1041-4.

Chaves AR, Leandro FZ, Carris JA, Queiroz MEC. Microextraction in packed sorbent for analysis of antidepressants in human plasma by liquid chromatography and spectrophotometric detection. J Chromatogr B. 2010; 878:2123-9.

Clark ZD, Cutler JM, Pavlov IY, Strathmann FG, Frank EL. Simple dilute-andshoot method for urinary vanillylmandelic acid and homovanillic acid by liquid chromatography tandem mass spectrometry. Clin Chim Acta. 2017; 468:201-8.

Davidson DF. Simultaneous assay for urinary 4-hydroxy-3-methoxymandelic acid, 5-hydroxyindoleacetic acid and homovanillic acid by isocratic HPLC with electrochemical detection. Ann Clin Biochem. 1989;26:137-43.

Fang LY, LV Y, Sheng XF, Yao SS. Sensitive, rapid and easy Analysis of three catecholamine metabolites in human urine and serum by liquid chromatography tandem mass spectrometry. J Chromatogr Sci. 2012;50: 450-6.

Grouzmann E, Centeno C, Eugster PJ. Quantification of vanillylmandelic acid, homovanillic acid and 5-hydroxyindoleacetic acid in urine using a dilute-andshoot and ultra-high pressure liquid chromatography tandem mass spectrometry method. Clin Chem Lab Med. 2018;59:1533-41.

Katayev A, Balciza C, Seccombe DW. Establishing reference intervals for clinical laboratory test results: is there a better way? Am J Clin Pathol. 2010:133:180-6.

Konieczna L, Roszkowska A, Niedzwiecki M, Baczek T. Hydrophilic interaction chromatography combined with dispersive liquid-liquid microextraction as a preconcentration tool for the simultaneous determination of the panel of underivatized neurotransmitters in human urine samples. J Chromatogr A. 2016;1431:111-21. 
Kumar A, Hart JP, McCalley DV. Determination of catecholamines in urine using hydrophilic interaction chromatography with electrochemical detection. J Chromatogr A. 2011;1218:3854-61.

Lionetto L, Lostia AM, Stigliano A, Cardelli P, Simmaco M. HPLC-mass spectrometry method for quantitative detection of neuroendocrine tumor markers: vanillylmandelic acid, homovanillic acid and 5-hydroxyindoleacetic acid. Clin Chim Acta. 2008;398:53-6.

Magera MJ, Thompson AL, Matern D, Rinaldo P. Liquid chromatography-tandem mass spectrometry method for the determination of vanillylmandelic acid in urine. Clin Chem. 2003;49:825-6.

Moein M, Abdel-Rehim A, Abdel-Rehim M. On-line determination of sarcosine in biological fluids utilizing dummy molecularly imprinted polymers in microextraction by packed sorbent. J Sep Sci. 2014;38:788-95.

Monteleone M, Naccarato A, Sindona G, Tagarelli A. A reliable and simple method for the assay of neuroendocrine tumor markers in human urine by solid-phase microextraction-gas chromatography-triple quadrupole mass spectrometry. Anal Chem Acta. 2013;759:66-73.

Saracino MA, Santarcangelo L, Raggi MA, Mercolini L. Microextraction by packed sorbent (MEPS) to analyze catecholamines in innovative biological samples. J Pharm Biomed Anal. 2015;104:122-9.

Shen Y, Li HJ, Lu J, Luo X, Guan Q, Cheng LM. Analytical validation and clinical application of urinary vanillyImandelic acid and homovanillic acid by LC-MS/ MS for diagnosis of neuroblastoma. Biomed Chromatogr. 2019:e4484.

Shen Y, Lu J, Tang Q, Guan Q, Sun ZY, Li HJ, Cheng LM. Rapid, easy analysis of urinary vanillylmandelic acid for diagnostic testing of pheochromocytoma by liquid chromatography tandem mass spectrometry. J Chromatogr B. 2015; 1002:92-7.

Taran F, Bernard H, Valleix A, Creminon C, Grassi J, Olichon D, Deverre JR, Pradelles $P$. Competitive enzyme immunoassay for urinary vanillylmandelic acid. Clin Chim Acta. 1997;264:177-92.

Tran MTC, Baglin J, Tran TT, Hoang KT, Phung LT, Read A, Greaves RF. Development of a new biochemical test to diagnose and monitor neuroblastoma in vietnam: Homovanillic and vanillylmandelic acid by gas chromatography-mass spectrometry. Clin Biochem. 2014;47:206-15.

Tsunoda M. Recent advances in methods for the analysis of catecholamines and their metabolites. Anal Bioanal Chem. 2006;386:506-14.

\section{Publisher's Note}

Springer Nature remains neutral with regard to jurisdictional claims in published maps and institutional affiliations.

\section{Submit your manuscript to a SpringerOpen ${ }^{\circ}$ journal and benefit from:}

- Convenient online submission

- Rigorous peer review

- Open access: articles freely available online

- High visibility within the field

- Retaining the copyright to your article

Submit your next manuscript at $\boldsymbol{\nabla}$ springeropen.com 